ORIGINAL ARTICLE

\title{
Occupational silica exposure and risk of various diseases: an analysis using death certificates from 27 states of the United States
}

\author{
G M Calvert, F L Rice, J M Boiano, J W Sheehy, W T Sanderson
}

See end of article for authors' affiliations

Correspondence to: Dr G M Calvert, National Institute for Occupational Safety \& Health, 4676 Columbia Parkway, R-21,

Cincinnati, OH 45226, USA; JAC6@CDC.GOV

Accepted 20 June 2002
Background: Although crystalline silica exposure is associated with silicosis, lung cancer, pulmonary tuberculosis, and chronic obstructive pulmonary disease (COPD), there is less support for an association with autoimmune disease, and renal disease.

Methods: Using data from the US National Occupational Mortality Surveillance (NOMS) system, a matched case-control design was employed to examine each of several diseases (including silicosis, lung cancer, stomach cancer, oesophageal cancer, COPD, pulmonary tuberculosis, sarcoidosis, systemic lupus erythematosus, systemic sclerosis, rheumatoid arthritis, and various types of renal disease). Cases were subjects whose death certificate mentioned the disease of interest. A separate control group for each of the diseases of interest was selected from among subjects whose death certificate did not mention the disease of interest or any of several diseases reported to be associated with crystalline silica exposure. Subjects were assigned into a qualitative crystalline silica exposure category based on the industry/occupation pairing found on their death certificate. We also investigated whether silicotics had a higher risk of disease compared to those without silicosis.

Results: Those postulated to have had detectable crystalline silica exposure had a significantly increased risk for silicosis, COPD, pulmonary tuberculosis, and rheumatoid arthritis. In addition, a significant trend of increasing risk with increasing silica exposure was observed for these same conditions and for lung cancer. Those postulated to have had the greatest crystalline silica exposure had a significantly increased risk for silicosis, lung cancer, COPD, and pulmonary tuberculosis only. Finally, those with silicosis had a significantly increased risk for COPD, pulmonary tuberculosis, and rheumatoid arthritis.

Conclusions: This study corroborates the association between crystalline silica exposure and silicosis, lung cancer, COPD, and pulmonary tuberculosis. In addition, support is provided for an association between crystalline silica exposure and rheumatoid arthritis.
C rystalline silica (for example, quartz) is a ubiquitous mineral dust found worldwide. The National Institute for Occupational Safety and Health (NIOSH) estimates that approximately 3 million US workers are exposed to this mineral (unpublished data, 1990). Industries and occupations having the potential for crystalline silica exposure include mining, quarrying, tunnelling, foundry work, glass manufacture, abrasive blasting, ceramic and pottery production, and cement and concrete production.

There is strong epidemiological evidence to support an association between occupational crystalline silica exposure and several diseases such as silicosis, lung cancer, pulmonary tuberculosis, and chronic obstructive pulmonary disease (COPD). ${ }^{1}$ There are other diseases that may be associated with occupational crystalline silica exposure, including autoimmune diseases (for example, systemic sclerosis, systemic lupus erythematosus, and rheumatoid arthritis), and renal diseases (for example, glomerulonephritis). ${ }^{1}$ However, the epidemiological support for these other diseases is less extensive, consisting of individual case series and a few epidemiological studies only. It has also been suggested that sarcoidosis may be associated with silica exposure. ${ }^{2}$

To address the need for more research on the association between crystalline silica exposure and these autoimmune related and renal disorders, we analysed data from the US National Occupational Mortality Surveillance (NOMS) system. NOMS is a collaborative effort between NIOSH, the National Center for Health Statistics, the National Cancer Institute, and selected state health departments. It augments the mortality vital statistics system with coded industry and occupation data. This report uses NOMS data from 27 states of the United States from 1982 to 1995. Specifically, we used a matched case-control design to investigate the association between potential occupational crystalline silica exposure and mortality from each of the diseases noted above, while controlling for the effects of age, race, gender, state of residence, and year of death. For each of the diseases examined, this effort included more disease cases than any previous study of occupational crystalline silica exposure.

\section{METHODS}

Death certificate data (from 27 states for the period from 1982 to 1995) contained in the NOMS database were used. The underlying and all contributory causes of death, the usual occupation, and various demographic variables were coded. The underlying and all mentioned causes of death were coded using the International Classification of Diseases, 9th revision (ICD-9). Cases were those subjects whose death certificate

Abbreviations: ANCA, antineutrophil cytoplasmic antibody; COPD, chronic obstructive pulmonary disease; ESRD, end stage renal disease; IARC, International Agency for Research on Cancer; ICD, International Classification of Diseases; MOR, mortality odds ratio; $\mathrm{NIOSH}$, National Institute for Occupational Safety and Health; NOMS, National Occupational Mortality Surveillance; PEL, permissible exposure limit; SLE, systemic lupus erythematosus 


\section{Main messages}

- This study corroborates the association between crystalline silica exposure and silicosis, lung cancer, pulmonary tuberculosis, and COPD.

- It provides support for an association between crystalline silica exposure and rheumatoid arthritis.

- It corroborates evidence that silicotics have an increased risk for COPD, pulmonary tuberculosis, and rheumatoid arthritis.

\section{Policy implications}

- Occupational crystalline silica dust exposure appears to be a risk factor for several diseases. NIOSH recommends an exposure limit of $0.05 \mathrm{mg} / \mathrm{m}^{3}$. To reduce disease risk, NIOSH recommends substituting less hazardous materials for crystalline silica when feasible, using appropriate respiratory protection when controls cannot keep exposures below the recommended limit, and making medical examinations available to exposed workers.

mentioned the disease of interest. Each of the diseases of interest were analysed separately. The diseases of interest included: silicosis (ICD-9 code 502), lung cancer (ICD-9 code 162), stomach cancer (ICD-9 code 151), oesophageal cancer (ICD-9 code 150), COPD (ICD-9 codes 490-492), pulmonary tuberculosis (ICD-9 codes 011, 012), sarcoidosis (ICD-9 code 135), systemic lupus erythematosus (ICD-9 code 710.0), systemic sclerosis (ICD-9 code 710.1), rheumatoid arthritis (ICD-9 codes 714.0, 714.1, 714.2), acute renal failure (ICD-9 code 584), chronic renal failure (ICD-9 code 585), renal disease not specified as acute or chronic (ICD-9 code 583), all renal failure (ICD-9 codes 580-586), acute glomerulonephritis (ICD-9 code 580), chronic glomerulonephritis (ICD-9 codes 581, 582), proliferative glomerulonephritis (ICD-9 codes 580.0, 581.0, 582.0, 583.0), membranous glomerulonephritis (ICD-9 codes 581.1, 582.1, 583.1), membranoproliferative glomerulonephritis (ICD-9 codes 581.2, 582.2, 583.2), minimal change glomerulonephritis (ICD-9 code 581.3), and rapidly progressive glomerulonephritis (ICD-9 codes 580.4, 582.4, 583.4).

A separate control group was selected for each of the diseases of interest. Controls were selected from among subjects whose death certificate did not mention the disease of interest or any of several diseases reported to be associated with crystalline silica exposure. Subjects were ineligible to be a control if any of the following diseases were listed on their death certificate: the specific disease of interest, pulmonary tuberculosis (ICD-9 codes 011, 012), silicosis (ICD-9 code 502), lung cancer (ICD-9 code 162), COPD (ICD-9 codes 490492 ), renal glomerular disease (ICD-9 code 580-583), connective tissue disease (ICD-9 code 710), or rheumatoid arthritis and related conditions (ICD-9 code 714). Five controls were matched to each case based on sex, race, state of residence, five year age group, and year of death group (1982-88, 1989-92, 1993-95). The occupation and industry provided on each death certificate was coded with Bureau of the Census Occupation Codes, and Bureau of the Census Industry Codes, respectively, according to the 1980 Bureau of the Census classification. ${ }^{3}$ Excluded from being a case or control were any death certificates that listed occupation and industry as retiree, homemaker, or unemployed, and those with no occupation and industry listed. Cases and controls had to be at least 18 years of age. Subjects who were neither Caucasian nor African-American were excluded because of small numbers.

\section{Exposure assessment}

A master list of industry/occupation pairings was obtained from death certificates collected between 1984 and 1986. This three year period was thought sufficient to identify the vast majority of industry/occupation pairings; however, some uncommon pairings may have been missed. Each occupation/ industry pairing was assigned into a crystalline silica exposure category of either "super high", "high", "medium", or "low/no" by a panel of three senior NIOSH certified industrial hygienists with experience assessing silica exposures (JMB, JWS, and WTS). They used professional experience and up to date technical references on crystalline silica to guide their exposure category assignments. The industrial hygienists were blinded to the diseases listed on the death certificate. The super high category was assigned to those occupation/ industry pairings judged to involve tasks with crystalline silica exposures that are five times greater than the OSHA permissible exposure limit (PEL). The high exposure category was assigned to those occupation/industry pairings judged to involve tasks with crystalline silica exposures at or above the OSHA PEL, but which did not meet the criteria for the super high category. Those in the super high and high categories were judged to have frequent silica exposure. The medium exposure category was assigned to those occupation/industry pairings judged to occasionally involve tasks with detectable crystalline silica exposures but which were considered below the OSHA permissible exposure limit. Finally, the "low/no" exposure category was assigned to those occupation/industry pairings judged to have little or no potential for crystalline silica exposure. Category assignments for each occupation/ industry pairing were initially made independently by two of the industrial hygienists. When the crystalline silica exposure category for a specific industry/occupation pairing differed between the two industrial hygienists, the third NIOSH industrial hygienist provided an independent classification (he was blinded to the categories previously assigned by the other two industrial hygienists). In most cases, the silica exposure category assigned by the third industrial hygienist matched one of the two earlier category assignments, and this category was assigned to the industry/occupation pairing. In a few instances, each of the three industrial hygienists assigned a different category to the industry/occupation pairing. A meeting was held and consensus was reached by the three industrial hygienists for these industry/occupation pairings. Study subjects were assigned a crystalline silica exposure category based on the industry/occupation pairing found on their death certificate. Table 1 lists the occupation/industry pairings assigned to the super high exposure category. A listing of industry/occupations assigned to each of the other exposure categories is available from the corresponding author.

Recognising that this exposure assessment approach has limitations, we also examined disease prevalence among silicotics (that is, silicosis was mentioned as the underlying or a contributing cause of death on the death certificate) compared to those without silicosis. Those with silicosis likely had a history of substantial silica exposure, and silicosis may be related to susceptibility for developing other diseases. In these analyses, controls were selected as described earlier, except that the control subjects could have any disease listed on their death certificate other than silicosis.

\section{Analysis of data}

All analyses were carried out with SAS procedures (SAS Institute, Cary, North Carolina, USA). For each of the diseases of interest, mortality odds ratios (MORs) were estimated by conditional logistic regression using the PROC PHREG procedure, and $95 \%$ confidence intervals were estimated using the Wald test. The effect of silica exposure was assessed by comparing subjects in the medium, high, and super high crystalline silica exposure categories to those in the low/no crystalline silica 
Table 1 List of industry/occupation pairings that were assigned to the super high crystalline silica exposure category

\begin{tabular}{ll}
\hline Industry (BOC)* & Occupation (BOC)† \\
\hline Metal mining (040) & Earth drillers (598); crushing and grinding machine operators (768) \\
Coal mining (041) & Earth drillers (598); oil well drillers (614) \\
Crude petroleum and natural gas extraction (042) & Earth drillers (598); \\
Non-metallic mining and quarrying, except fuel (050) & Earth drillers (598); mining machine operators (616); operating engineers (844); \\
& labourers, except construction (889) \\
Construction (060) & Earth drillers (598) \\
Cement, concrete, gypsum, and plaster products (251) & Labourers, except construction (889) \\
Pottery and related products (261) & Crushing and grinding machine operators (768) \\
Miscellaneous non-metallic mineral and stone products (262) & Slicing and cutting machine operators (769) \\
Iron and steel foundries (271) & Moulding and casting machine operators (719); labourers, except construction (889) \\
Construction and material handling machines (312) & Earth drillers (598) \\
Not specified manufacturing industries (392) & Earth drillers (598) \\
\hline
\end{tabular}

* 1980 US Bureau of the Census classification code for industry; $† 1980$ US Bureau of the Census classification code for occupation.

Table 2 Number of death certificates excluded from all analyses, and the reason for the exclusions

\begin{tabular}{lr}
\hline Reason for exclusion & Number (\%) \\
\hline Race not Caucasian or African-American & $39404(1.7)$ \\
Age (less than 18 years or greater than 119 years) & $1644(0.1)$ \\
Occupation and/or industry = retiree, homemaker, unemployed, or no occupation & $2273189(98.2)$ \\
and industry was listed & 2314237 (100) \\
Total excluded & \\
\hline
\end{tabular}

exposure category, and MORs with 95\% confidence intervals were determined. The statistical significance of linear trend with increasing exposure category was tested by assuming the categories were evenly spaced and dividing the regression coefficient of the variable by its standard error. In addition, those postulated to have detectable crystalline silica exposures (that is, those in the medium, high, and super high silica exposure categories) were combined and compared to those with a low/no crystalline silica exposure classification. Given the interest in disease risk among non-silicotics, separate

Table 3 Information on cases and controls for each disease of interest: total numbers, proportion in each crystalline silica exposure category, mean age, sex, and race

\begin{tabular}{|c|c|c|c|c|c|c|c|c|c|}
\hline \multirow[b]{2}{*}{ Disease } & \multirow[b]{2}{*}{ Case/control } & \multirow{2}{*}{$\begin{array}{l}\text { Total } \\
\text { deaths }\end{array}$} & \multicolumn{4}{|c|}{ Proportion in each silica exposure category } & \multirow{2}{*}{$\begin{array}{l}\text { Mean age } \\
\text { at death }(y)\end{array}$} & \multirow{2}{*}{$\begin{array}{l}\text { Male } \\
(\%)\end{array}$} & \multirow{2}{*}{$\begin{array}{l}\text { Caucasian } \\
(\%)\end{array}$} \\
\hline & & & Low/no & Medium & High & Super high & & & \\
\hline \multirow[t]{2}{*}{ Silicosis } & Cases & 1237 & 49.2 & 18.0 & 26.6 & 6.2 & 74 & 97 & 86 \\
\hline & Controls & 6185 & 81.9 & 10.9 & 6.8 & 0.4 & & & \\
\hline \multirow[t]{2}{*}{ Lung cancer } & Cases & 396481 & 86.9 & 6.9 & 5.9 & 0.3 & 68 & 78 & 90 \\
\hline & Controls & 1964005 & 86.8 & 7.8 & 5.2 & 0.2 & & & \\
\hline \multirow[t]{2}{*}{ Stomach cancer } & Cases & 35221 & 86.8 & 7.6 & 5.4 & 0.2 & 70 & 75 & 84 \\
\hline & Controls & 176079 & 86.6 & 7.9 & 5.2 & 0.3 & & & \\
\hline \multirow[t]{2}{*}{ Oesophageal cancer } & Cases & 28245 & 86.3 & 7.0 & 6.4 & 0.3 & 67 & 85 & 81 \\
\hline & Controls & 141209 & 85.6 & 8.2 & 5.9 & 0.3 & & & \\
\hline \multirow[t]{2}{*}{ COPD } & Cases & 94922 & 85.1 & 8.6 & 6.0 & 0.3 & 73 & 77 & 95 \\
\hline & Controls & 474564 & 86.4 & 8.7 & 4.7 & 0.2 & & & \\
\hline \multirow[t]{2}{*}{ Pulmonary tuberculosis } & Cases & 6570 & 78.2 & 11.7 & 9.5 & 0.6 & 68 & 80 & 66 \\
\hline & Controls & 32843 & 83.5 & 9.7 & 6.5 & 0.3 & & & \\
\hline \multirow[t]{2}{*}{ Sarcoidosis } & Cases & 2036 & 93.3 & 3.6 & 2.9 & 0.2 & 54 & 48 & 39 \\
\hline & Controls & 10165 & 90.4 & 4.7 & 4.7 & 0.2 & & & \\
\hline \multirow[t]{2}{*}{ Systemic sclerosis } & Cases & 2875 & 93.6 & 3.4 & 2.8 & 0.2 & 64 & 34 & 81 \\
\hline & Controls & 14363 & 93.6 & 3.8 & 2.5 & 0.1 & & & \\
\hline \multirow[t]{2}{*}{ Systemic lupus erythematosus } & Cases & 3733 & 94.1 & 3.5 & 2.3 & 0.1 & 59 & 28 & 71 \\
\hline & Controls & 18625 & 93.6 & 3.9 & 2.4 & 0.1 & & & \\
\hline \multirow[t]{2}{*}{ Rheumatoid arthritis } & Cases & 18335 & 89.5 & 7.1 & 3.2 & 0.2 & 74 & 48 & 93 \\
\hline & Controls & 91660 & 90.8 & 6.0 & 3.0 & 0.2 & & & \\
\hline \multirow[t]{2}{*}{ All renal failure } & Cases & 279378 & 86.6 & 8.7 & 4.5 & 0.2 & 74 & 69 & 83 \\
\hline & Controls & 1395726 & 86.4 & 8.8 & 4.6 & 0.2 & & & \\
\hline \multirow[t]{2}{*}{ Chronic renal failure } & Cases & 56521 & 86.6 & 8.8 & 4.4 & 0.2 & 74 & 68 & 77 \\
\hline & Controls & 282492 & 86.2 & 8.9 & 4.7 & 0.2 & & & \\
\hline \multirow[t]{2}{*}{ Acute renal failure } & Cases & 47942 & 86.7 & 8.5 & 4.6 & 0.2 & 74 & 70 & 86 \\
\hline & Controls & 239644 & 86.4 & 8.8 & 4.6 & 0.2 & & & \\
\hline \multirow[t]{2}{*}{ Chronic glomerulonephritis } & Cases & 12563 & 86.4 & 9.3 & 4.1 & 0.2 & 75 & 69 & 78 \\
\hline & Controls & 62804 & 85.2 & 9.8 & 4.8 & 0.2 & & & \\
\hline \multirow[t]{2}{*}{ Membranous glomerulonephritis } & Cases & 194 & 88.6 & 5.7 & 5.7 & 0 & 66 & 77 & 86 \\
\hline & Controls & 970 & 87.5 & 5.9 & 6.2 & 0.4 & & & \\
\hline
\end{tabular}


Table 4 Conditional logistic regression results for various diseases of interest

\begin{tabular}{|c|c|c|c|c|c|}
\hline \multirow[b]{2}{*}{ Disease } & \multicolumn{4}{|c|}{ Mortality odds ratio ( $95 \%$ confidence interval) by silica exposure category } & \multirow{2}{*}{$\begin{array}{l}\text { - Trend direction, } \\
\mathrm{p} \text { value }\end{array}$} \\
\hline & Ever* low/no & Medium $v$ low/no & High $v$ low/no & Super high $v$ low/no & \\
\hline Silicosis & $4.98(4.35$ to 5.71$)$ & $2.91(2.43$ to 3.48$)$ & $6.84(5.73$ to 8.16$)$ & $30.5(18.4$ to 50.5$)$ &,$+ p<0.001$ \\
\hline Lung cancer & $0.99(0.98$ to 1.00$)$ & $0.88(0.87$ to 0.90$)$ & $1.13(1.11$ to 1.15$)$ & $1.13(1.06$ to 1.21$)$ &,$+ p<0.001$ \\
\hline Stomach cancer & $0.98(0.95$ to 1.02$)$ & $0.95(0.91$ to 1.00$)$ & 1.04 (0.99 to 1.09 ) & 0.81 (0.64 to 1.03$)$ &,- NS \\
\hline Oesophageal cancer & $0.94(0.91$ to 0.98$)$ & $0.85(0.81$ to 0.89$)$ & 1.07 (1.01 to 1.13$)$ & $1.14(0.90$ to 1.43$)$ &,- NS \\
\hline COPD & $1.12(1.10$ to 1.14$)$ & $1.02(0.99$ to 1.04$)$ & 1.29 (1.25 to 1.33$)$ & $1.47(1.30$ to 1.66$)$ &,$+ p<0.001$ \\
\hline Pulmonary tuberculosis & 1.47 (1.37 to 1.57$)$ & 1.34 (1.23 to 1.47$)$ & 1.60 (1.45 to 1.76$)$ & 2.48 (1.68 to 3.65$)$ &,$+ p<0.001$ \\
\hline Sarcoidosis & $0.66(0.54$ to 0.80$)$ & $0.73(0.57$ to 0.94$)$ & $0.58(0.44$ to 0.76$)$ & $1.02(0.29$ to 3.56$)$ &,- NS \\
\hline Systemic sclerosis & $1.00(0.84$ to 1.19$)$ & $0.91 \quad(0.72$ to 1.14$)$ & $1.08(0.84$ to 1.40$)$ & $2.14(0.82$ to 5.57$)$ & + NS \\
\hline Systemic lupus erythematosus & $0.94(0.80$ to 1.10$)$ & 0.88 (0.72 to 1.08$)$ & 1.01 (0.79 to 1.29 ) & 1.37 (0.51 to 3.69$)$ &,$- N S$ \\
\hline Rheumatoid arthritis & $1.19(1.12$ to 1.25$)$ & $1.23(1.15$ to 1.31$)$ & 1.11 (1.01 to 1.22$)$ & 1.05 (0.70 to 1.57$)$ &,$+ p<0.001$ \\
\hline All renal failure & 0.98 (0.97 to 0.99 ) & $0.99(0.98$ to 1.01$)$ & $0.96(0.94$ to 0.98$)$ & $1.01(0.92$ to 1.10$)$ &,$- p<0.001$ \\
\hline Acute renal failure & 0.97 (0.94 to 1.00$)$ & $0.96(0.93$ to 1.00$)$ & 0.99 (0.95 to 1.04$)$ & $1.01(0.82$ to 1.24$)$ &,- NS \\
\hline Chronic renal failure & 0.96 (0.94 to 0.99 ) & $0.98(0.95$ to 1.01$)$ & $0.93(0.89$ to 0.98$)$ & $1.00(0.83$ to 1.21$)$ &,$- p=0.003$ \\
\hline Chronic glomerulonephritis & $0.90(0.85$ to 0.96$)$ & $0.93(0.87$ to 1.00$)$ & 0.85 (0.77 to 0.94$)$ & $0.70(0.45$ to 1.10$)$ &,$- p<0.001$ \\
\hline Membranous glomerulonephritis & 0.89 (0.53 to 1.48$)$ & $0.93(0.47$ to 1.85$)$ & 0.89 (0.45 to 1.77$)$ & - & - NS \\
\hline
\end{tabular}

COPD, chronic obstructive pulmonary disease; NS, non-significant.

${ }^{*}$ Ever $=$ medium, high, and super high categories combined.

+ , increasing disease risk with increasing crystalline silica exposure category; -, decreasing disease risk with increasing crystalline silica exposure category.

Table 5 Mortality odds ratios and 95\% confidence intervals for various diseases among those with silicosis compared to a non-silicotic control group

\begin{tabular}{|c|c|c|c|}
\hline Disease & $\begin{array}{l}\text { Number }(\%) \text { of silicotics } \\
\text { with disease of interest } \\
(n=1237)\end{array}$ & $\begin{array}{l}\text { Number (\%) of controls } \\
\text { with disease of interest } \\
(n=6185)\end{array}$ & $\begin{array}{l}\text { Mortality odds ratio } \\
(95 \% \mathrm{CI})\end{array}$ \\
\hline Lung cancer & $84(6.8)$ & $575(9.3)$ & $0.70(0.55$ to 0.89$)$ \\
\hline Stomach cancer & $2(0.2)$ & $39(0.6)$ & $0.25(0.06$ to 1.06$)$ \\
\hline Oesophageal cancer & $3(0.2)$ & 57 (0.9) & $0.26(0.08$ to 0.83$)$ \\
\hline COPD & $117(9.5)$ & $150(2.4)$ & 4.38 (3.39 to 5.67$)$ \\
\hline Pulmonary tuberculosis & 48 (3.9) & $7(0.1)$ & $39.5 \quad(16.9$ to 92.4$)$ \\
\hline Sarcoidosis & 0 & $3(0.1)$ & - \\
\hline Systemic sclerosis & $2(0.2)$ & $5(0.1)$ & $2.00(0.39$ to 10.31$)$ \\
\hline Systemic lupus erythematosus & 0 & $3(0.1)$ & - \\
\hline Rheumatoid arthritis & $15(1.2)$ & $20(0.3)$ & 3.75 (1.92 to 7.32$)$ \\
\hline All renal failure & $35(2.8)$ & $417(6.7)$ & $0.40(0.28$ to 0.57$)$ \\
\hline Acute renal failure & $8(0.7)$ & $60(1.0)$ & 0.67 (0.32 to 1.39$)$ \\
\hline Chronic renal failure & $3(0.2)$ & $84(1.4)$ & $0.18(0.06$ to 0.56$)$ \\
\hline Chronic glomerulonephritis & $2(0.2)$ & $10(0.2)$ & $1.00(0.22$ to 4.56$)$ \\
\hline Membranous glomerulonephritis & $1(0.08)$ & $2(0.03)$ & $2.32(0.21$ to 25.63$)$ \\
\hline
\end{tabular}

analyses were conducted in which the disease cases with concomitant silicosis and their associated controls were excluded. Because these exclusions made little difference in the findings compared to those provided in table 4, these analyses are not reported. In addition, the prevalence of various diseases among those with silicosis was compared to those without silicosis using the same PROC PHREG procedure. No other variables were placed in the regression models. Although separate analyses were conducted that only included males, these findings are not provided because they were similar to the findings provided for males and females combined.

\section{RESULTS}

Of the 7153468 death certificates in the NOMS database, 4839231 (68\%) were available for analysis. Table 2 provides the reasons the other $32 \%$ of death certificates were rejected. An additional 529916 death certificates were ineligible to serve as a control because they included an exclusionary cause of death.

Table 3 provides demographic data on cases and controls for most of the diseases of interest. For each of the included diseases of interest, this table provides the number of case and control deaths, the proportion in each crystalline silica exposure category, the mean age at death, the proportion who were male, and the proportion who were Caucasian.
Table 4 provides the MORs for most of the diseases of interest. Among those in the detectable crystalline silica exposure group (that is, those in the medium, high, and super high silica exposure categories combined), significant increases in risk were observed for silicosis, COPD, pulmonary tuberculosis, and rheumatoid arthritis. A significant trend of increasing risk with increasing silica exposure was observed for these same conditions. Although the trend was significant for rheumatoid arthritis, a monotonic increase in risk with increasing crystalline silica exposure category was not observed, suggesting that this association may not be linear. Monotonic increases in risk with increasing crystalline silica exposure category were observed for systemic sclerosis, and systemic lupus erythematosis; however, the trend was not significant. Those postulated to have the greatest crystalline silica exposure (that is, those in the super high silica exposure category) had a significantly increased risk for silicosis, lung cancer, COPD, and pulmonary tuberculosis only.

Table 5 provides a summary of disease risks among silicotics compared to non-silicotics. Those with silicosis had a significantly increased risk for COPD, pulmonary tuberculosis, and rheumatoid arthritis. In addition, silicotics had a significantly reduced risk of lung cancer, oesophageal cancer, and renal failure. No meaningful difference in results was found when the non-silicotic controls with industry/ 
occupation pairings assigned into the "high" and "super high" silica exposure categories were excluded (these controls accounted for $7.5 \%$ of all the controls).

The findings for proliferative glomerulonephritis, membranoproliferative glomerulonephritis, minimal change glomerulonephritis, rapidly progressive glomerulonephritis, and acute glomerulonephritis are not provided in tables 3-5. For each of these conditions the MOR was less than one in the comparison between those postulated to have detectable crystalline silica exposure and those with low/no crystalline silica exposure. With the exception of acute glomerulonephritis $($ MOR $=0.78,95 \%$ CI 0.63 to 0.97$)$, the MORs were not significantly less than one. In addition, none of these renal outcomes had a monotonic increase in risk with increasing crystalline silica exposure category. In the comparison of silicotics versus non-silicotics, none of the subjects had any of these five renal diseases.

\section{DISCUSSION}

Our study has several strengths. There were 4839231 death certificates from which to draw cases. The deaths occurred over a 14 year period and were from 27 different states. By applying a case-control design to this large national mortality database, the number of cases for each outcome of interest was often in the thousands. For each of the diseases analysed, this study had more disease cases than any previous study of occupational crystalline silica exposure.

Our methodology for assessing silica exposure was both a strength and a weakness. The rating of industry/occupation pairings for potential crystalline silica exposure by a panel of three senior industrial hygienists was considered a strength. Crystalline silica exposure was stratified into four categories, which is considered an improvement compared to relying on previously compiled but incomplete lists of silica exposed industries and occupations. Despite the limited industry and occupation information available on the death certificate, the finding of a dose-response relation for outcomes known to be associated with crystalline silica exposure (for example, silicosis, pulmonary tuberculosis, and COPD) provides validity to our methodology for rating crystalline silica exposure. Other researchers used a similar method to estimate other occupational exposures. ${ }^{45}$ It has also been observed that industrial hygiene panels may be best suited for assessing relatively common exposures, ${ }^{6}$ a criterion that silica exposure arguably meets.

The main limitation of our study also pertains to exposure assessment. Each of the industry-occupation pairings was rated on postulated crystalline silica exposure. No information was available on the actual crystalline silica exposure experienced by our study subjects (for example, no information was available on the specific tasks performed by the crystalline silica exposed worker; nor on the commencement, duration, and intensity of crystalline silica exposure). In addition, the industry and occupation on the death certificate may be the final, usual, or most prestigious job, ${ }^{7}$ and may reflect erroneous recollections of occupation and industry by the next of kin. ${ }^{8}$ Complete occupational histories were unavailable. Having incomplete occupational histories probably explains the finding that $49 \%$ of silicosis deaths had low/no crystalline silica exposure (table 3), as jobs with detectable crystalline silica exposure did not appear on these death certificates. Given the exposure limitations, a substantial amount of nondifferential misclassification likely attenuated our odds ratio estimates. ${ }^{9}$ However, it has been observed that non-differential misclassification is reduced when using a panel of experts compared to a single rater. ${ }^{6}$ In addition, to circumvent the limitations of our exposure assessment, we examined disease prevalence among silicotics compared to non-silicotics. The findings were similar with these two exposure assessment approaches, with the notable exception of conflicting findings for lung cancer.
Another limitation involves the diseases listed on the death certificate. The diagnoses provided on the death certificate may be erroneous or incomplete, leading to disease misclassification. ${ }^{10}{ }^{11}$ For example, it has been observed that some with a mention of silicosis may not have this disease. ${ }^{12}$ We attempted to minimise disease misclassification by using the underlying and contributing causes of death when identifying cases.

A final limitation is that information was not available on possible confounding factors such as diet, hobbies, tobacco use, alcohol use, or medications. However, we were able to control for age, race, gender, state of residence, and year of death by matching on these variables.

\section{Silicosis}

Silicosis is caused by the inhalation of respirable crystalline silica and has been recognised as a distinct disease since the late nineteenth century. ${ }^{13}$ However, silicosis prevention efforts continue because silicosis still occurs worldwide, even in developed countries. ${ }^{14-16}$ As expected, our findings show that silicosis was strongly associated with occupational crystalline silica exposure and there was a significant trend of increasing risk across the exposure categories. Workers in the "super high" crystalline silica exposure category had a mortality risk over 30 times greater than workers with "low/no" exposures, which is consistent with mortality study findings in industries with high potential crystalline silica exposures. ${ }^{17-23}$

\section{Trachea, bronchus, and lung cancer}

The International Agency for Research on Cancer (IARC) has recently determined that occupational exposure to respirable crystalline silica (that is, quartz and cristobalite forms) is carcinogenic to humans. ${ }^{24}$ Our findings support an association between high level crystalline silica exposure and lung cancer. The statistically significant MORs for high and super high exposures compared with low/no exposure $($ MORs $=1.13)$ are consistent with the relative risk of 1.3 reported in a meta-analysis of 16 cohort and case-control studies of lung cancer in crystalline silica exposed workers without silicosis. ${ }^{25}$ However, because the magnitude of the risks we observed was modest, could potentially be explained by smoking, and because white collar workers smoke less than blue collar workers,${ }^{26}$ we reanalysed our lung cancer data by excluding white collar workers (that is, those with Bureau of the Census occupation codes less than 403) from the control group Although this reanalysis found lower risks, our interpretation remains unchanged (high exposure category: 1.07 (1.061.09); super high exposure category: 1.08 (1.01-1.15)). Although many studies observed that silicotics have an increased risk for lung cancer, a few studies, including ours, found evidence suggesting the lack of such an association..$^{21}$ 27-28 Although this lack of consistency across studies may be related to differences in study design, it suggests that silicosis is not necessary for an increased risk of lung cancer among silica exposed workers. ${ }^{29}$

\section{Chronic obstructive pulmonary disease}

Both silicosis and crystalline silica exposure appear to be associated with bronchitis, COPD, and emphysema based on consistent epidemiological evidence. ${ }^{130}$ By finding consistently increased MORs among those in the medium and higher crystalline silica exposure categories, with a significant trend across these categories, our findings provide support for an association between crystalline silica exposure and COPD.

\section{Pulmonary tuberculosis}

The epidemiological studies conducted in the twentieth century firmly established the association between pulmonary tuberculosis and silicosis. ${ }^{31}$ In addition, studies have found 
increased incidences of pulmonary tuberculosis in nonsilicotic workers with long term crystalline silica exposures. ${ }^{32}{ }^{33}$ Our findings are consistent with these previous studies.

\section{Gastric cancer and oesophageal cancer}

There is equivocal evidence for an association between crystalline silica exposure and oesophageal cancer or gastric cancer. ${ }^{1}$ Occupational mortality studies have reported statistically significant excesses of deaths from stomach or gastric cancer in iron ore, gold, lead, and zinc miners, ${ }^{20}{ }^{34-39}$ foundry and other metal workers, ${ }^{40}$ jewellery workers, ${ }^{41-44}$ farmers, ${ }^{45}$ and farm workers. ${ }^{46}$ A case-control study of 250 male hospital patients in Canada found a statistically significant excess of pathologically confirmed stomach cancer among the 25 patients that reported a history of "substantial" occupational exposure to crystalline silica compared with 2822 controls (OR $=1.7 ; 95 \%$ CI 1.1 to 2.7 after adjusting for effects of age, birthplace, education, and cigarette smoking). ${ }^{47}$ Statistically significant excesses of deaths or cases of oesophageal cancer, ${ }^{39}{ }^{48}$ cancers of the digestive system, ${ }^{49}$ and intestinal or peritoneal cancer ${ }^{50-52}$ have been reported for workers that may have been exposed to crystalline silica. However, some well conducted, IARC reviewed studies ${ }^{24}$ that found increased risks of lung cancer for crystalline silica exposed workers or silicotics, either did not find significantly increased risks of gastric or oesophageal cancer, ${ }^{18505354}$ or the risks for these gastrointestinal cancers were not reported..$^{525556}$ Our study provides little support for an association between oesophageal cancer and crystalline silica exposure. We found a monotonic increase in MORs for oesophageal cancer across potential crystalline silica exposure categories, but the trend was not significant. In addition, none of the increased MORs were statistically significant and the risk of oesophageal cancer was not increased among silicotics compared to non-silicotics. Our data do not support an association between crystalline silica exposure and gastric cancer.

\section{Autoimmune related diseases}

Autoimmune disorders result from a breakdown in immune tolerance. The specific cause of the majority of autoimmune disorders is unknown. Multiple factors such as genes, infectious agents, hormones, environmental and occupational exposures, and lifestyle may be involved..$^{57} 58$

The cellular mechanism for the development of autoimmune diseases in crystalline silica exposed workers is not known. However, the mechanisms for most environmentally induced autoimmune diseases can be divided into three categories: release of autoreactive immune cells into circulation; modification of immune cell gene expression resulting in the ability of these cells to respond to signals that are normally insufficient to generate an immune response, which may lead to an autoimmune response; and modification of self antigens such that they are recognised as foreign by the immune system. ${ }^{59}$ Some of these mechanisms have been postulated to explain the role of crystalline silica exposure in autoimmune disease. $^{60}$

\section{Rheumatoid arthritis}

Based on the results of one case-control, ${ }^{61}$ and three registry linkage studies, ${ }^{62-64}$ the evidence for an association between silicosis and rheumatoid arthritis appears to be consistent. Our analysis of silicotics supports this conclusion. In contrast the evidence for an association between this disease and crystalline silica exposure is equivocal. One study of a Finnish granite worker cohort found a significantly increased incidence and prevalence of disabling rheumatoid arthritis among these workers compared to the general population. ${ }^{65}$ In contrast, a recent nested matched case-control study of 58 rheumatoid arthritis cases (43 men; 15 women) from a large cohort of 8325 pottery, sandstone, and refractory workers did not find a statistically significant association between exposure to respirable silica and rheumatoid arthritis. ${ }^{66}$ Finally, a matched case-control study of 281 male and female rheumatoid arthritis cases identified at a Swedish hospital and 507 population based controls found no exposures or occupations that were significantly associated with rheumatoid arthritis. ${ }^{67}$ Our study provides modest support for an association between crystalline silica exposure and rheumatoid arthritis. The MOR was statistically significant when all workers postulated to have detectable crystalline silica exposure were combined (MOR 1.19; 95\% CI 1.12 to 1.25 ). The trend in risk with increasing silica exposure did not appear linear, but may be related to limitations in our exposure assessment.

\section{Systemic sclerosis}

There is substantial evidence supporting an association between silicosis and systemic sclerosis. ${ }^{60}$ In our analysis, although only two silicotics had systemic sclerosis, the MOR of 2.0 (95\% CI 0.4 to 10.3 ) is suggestive of an association. However, the evidence for an association between this disease and crystalline silica exposure is equivocal. Five case-control studies of scleroderma or systemic sclerosis and crystalline silica exposure were published since 1990. Odds ratios were non-significantly increased among Michigan women potentially exposed to "silica dust, sand, or other silica products", ${ }^{6}$ and among crystalline silica exposed men from Italy and the United Kingdom. ${ }^{69}{ }^{70}$ A recent study of 160 Australian males living, deceased, or of unknown vital status with systemic sclerosis found a significant difference in the number of cases with occupational crystalline silica exposure compared with controls (OR $=3.93 ; 95 \%$ CI 1.84 to $8.54 ; 60 / 160$ cases and $11 / 83$ controls with potential crystalline silica exposure). ${ }^{71}$ After adjustment for socioeconomic status, the OR decreased to 2.51 ( $95 \%$ CI 1.28 to 4.98 ). In contrast, odds ratios were not increased among crystalline silica exposed women from Ohio. ${ }^{72}$ Our study provides limited support for an association between systemic sclerosis and crystalline silica exposure. Although we found a monotonic increase in risk, with non-significantly increased mortality risks among workers in the high and super high silica exposure categories, the trend was not significant.

\section{Systemic lupus erythematosus}

The dearth of well designed and conducted epidemiological studies of systemic lupus erythematosis (SLE) among crystalline silica exposed workers precludes any meaningful conclusion about an association between SLE and crystalline silica exposure or silicosis. One case-control study of SLE and crystalline silica exposure included 265 cases and 355 age, sex, and residence matched controls from the southern United States and found a statistically significant odds ratio for men working on tobacco farms (OR $=5.2 ; 95 \%$ CI 1.2 to 21.4 ) or working in pottery or ceramics manufacturing $(\mathrm{OR}=7.4 ; 95 \% \mathrm{CI}$ 1.4 to 37.1$).^{73}$ Another case-control study of 51 lupus nephritis cases and 51 controls with other forms of renal disease found no association between lupus nephritis and silica exposure ${ }^{74}$; however, given that silica exposure may be associated with some types of renal disease, the control group used in this study may not have been appropriate. Prevalence studies of scouring powder workers, and uranium miners offer suggestive evidence for an association between high level silica exposure and SLE. ${ }^{75} 76$ The SLE prevalence observed in these two studies was at least an order of magnitude higher than that estimated for the general population. A prevalence study of silicotics also found an association with SLE. ${ }^{62}$ We found a monotonic increase in risk with increasing crystalline silica exposure category; however the trend was not significant nor 
were any of the MORs. Our data provide limited evidence for an association between high level crystalline silica exposure and SLE.

\section{Sarcoidosis}

Sarcoidosis is a rare multisystem granulomatous disease of unknown aetiology. ${ }^{77}$ Apart from our study, we identified only one other study that examined the association between crystalline silica exposure and sarcoidosis. This case-control study in an Icelandic district with a diatomaceous earth processing plant included eight cases with sarcoidosis and 70 population based controls. ${ }^{2}$ Information on occupational exposure to crystalline silica (mainly cristobalite form) was obtained from employment records of plant workers and workers that loaded the product. A significant association was observed between employment in these capacities and sarcoidosis $(\mathrm{OR}=13.2$, 95\% CI 2.0 to 140.9). There was some indication of increased risk with increasing exposure when hours of work were stratified into two categories. However, there were few cases and controls in each category and the resulting 95\% confidence intervals were very wide. The findings from our study do not support those of Rafnsson and colleagues. ${ }^{2}$ Our analysis of 2036 deaths with sarcoidosis found no trend across categories of potential crystalline silica exposure and all MORs were less than one except in the super high exposure category, where the MOR approximated one (MOR 1.02; 95\% CI 0.29 to 3.56).

\section{Chronic glomerulonephritis and renal failure}

Several recent studies provide growing evidence for an association between renal disease and crystalline silica exposure. Small, clinic based matched case-control studies reported statistically significant associations between silica exposure (based on job history) and Wegener's granulomatosis, ${ }^{78}$ diseases with positive antineutrophil cytoplasmic antibody $(\mathrm{ANCA}+){ }^{79}$ and ANCA+ rapidly progressive glomerulonephritis. ${ }^{80}$ Significant associations between crystalline silica exposure and end stage renal disease (ESRD) caused by glomerulonephritis were identified in cohorts of crystalline silica exposed gold miners, ${ }^{81}$ and workers in the industrial sand industry. ${ }^{82}$ In addition, another cohort study of ceramics workers found that these workers had an increased risk for ESRD. ${ }^{83}$ A case-control study of men with ESRD found a significant association between crystalline silica exposure and ESRDD. ${ }^{84}$ In contrast, a study of nearly 600 cases of silicosis in Michigan did not find that duration of crystalline silica exposure or severity of radiographic fibrosis was related to increased prevalence of kidney disease ${ }^{85}$ However, there was a higher prevalence of increased serum creatinine concentrations among cases compared with matched controls. At least three cohort studies of silica exposed workers did not find significantly increased risks for renal disease mortality; none of these three studies examined specific types of renal disease separately, but instead lumped many renal diseases into a single category. ${ }^{86-88}$ Our findings of no significant association between crystalline silica exposure and several different renal diseases are in contrast to many recent studies. Death certificates can be an incomplete source of information. ${ }^{10}$ For example, one study found that only 4/7 (57\%) of deceased gold miners with ESRD had any renal disease mentioned on the death certificate.$^{81}$ However, if our study missed a true increase in risk, one would have to assume that renal diseases and/or silica exposed jobs are much more likely to be missing from death certificates of those with increased crystalline silica exposure compared to the general population.

\section{ACKNOWLEDGEMENTS}

The authors wish to thank Jim Walker, PhD for his advice on the National Occupational Mortality Survey, Kyle Steenland, PhD, Harvey
Checkoway, PhD, and Ken Rosenman, MD for kindly reviewing the manuscript, and Marty Petersen for sharing his statistical expertise.

\section{Authors' affiliations}

G M Calvert, J M Boiano, W T Sanderson, Division of Surveillance, Hazard Evaluations and Field Studies, National Institute for Occupational Safety and Health, Centers for Disease Control and Prevention, Cincinnati, Ohio, USA

F L Rice, Education and Information Division, National Institute for Occupational Safety and Health

J W Sheehy, Division of Applied Research and Technology, National Institute for Occupational Safety and Health

\section{REFERENCES}

1 WHO. Crystalline silica, quartz. Concise International Chemical Assessment Document (CICAD) No. 24. Geneva, Switzerland: World Health Organization, 2000.

2 Rafnsson V, Ingimarsson $\mathrm{O}$, Hjalmarsson I, et al. Association between exposure to crystalline silica and risk of sarcoidosis. Occup Environ Med 1998;55:657-60.

3 US Bureau of the Census. 1980 census of the population: alphabetical index of industries and occupations, 2nd edition. Washington, DC: US Department of Commerce, Bureau of the Census, 1981.

4 Goldberg MS, Siemiatycki J, Gerin M. Inter-rater agreement in assessing occupational exposure in a case-control study. $\mathrm{Br} J$ Ind Med 1986;43:667-76

5 Clavel J, Mandereau L, Conso F, et al. Occupational exposure to solvents and hairy cell leukaemia. Occup Environ Med 1998;55:59-64.

6 Benke G, Sim M, Forbes A, et al. Retrospective assessment of occupational exposure to chemicals in community-based studies: validity and repeatability of industrial hygiene panel ratings. Int J Epidemiol 1997; 26:635-42.

7 Checkoway H, Pearce N, Crawford-Brown DJ. Research methods in occupational epidemiology. New York: Oxford University Press, 1989

8 Steenland K, Beaumont J. The accuracy of occupation and industry data on death certificates. J Occup Med 1984;26:288-96.

9 Stewart PA, Carel R, Schairer C et al. Comparison of industrial hygienists' exposure evaluations for an epidemiologic study. Scand Work Environ Health 2000;26:44-51.

10 Kircher T, Nelson J, Burdo H. The autopsy as a measure of accuracy of the death certificate. N Engl J Med 1985;313:1263-9.

11 Engel LW, Strauchen JA, Chiazze L, et al. Accuracy of death certification in an autopsied population with specific attention to malignant neoplasms and vascular diseases. Am J Epidemiol 1980;111:99-112

12 Rosenman KD, Hogan A, Reilly M. What is the most cost-effective way to identify silica problem worksites? Am J Ind Med 2001;39:629-35.

13 Harley RA, Vallyathan V. History of silicosis. In: Castranova V, Vallyathan V, Wallace WE, eds. Silica and silica-induced lung diseases. Boca Raton, FL: CRC Press, 1996:7-13.

14 WHO. WHO calls for medical surveillance of workers exposed to mineral dusts. Geneva, Switzerland: World Health Organization, Press release $\mathrm{WHO} / 73,1993$.

15 Wagner GR. The inexcusable persistence of silicosis [editorial]. Am J Public Health 1995;85:1346-7.

16 NIOSH. NIOSH Hazard Review: Health effects of occupational exposure to respirable crystalline silica. DHHS (NIOSH) Publication No. 2002-129. Cincinnati, OH, US Department of Health and Human Services, Public Health Service, Centers for Disease Control and Prevention, National Institute for Occupational Safety and Health, 2002.

17 Chen J, McLaughlin JK, Zhang JY, et al. Mortality among dust-exposed Chinese mine and pottery workers. J Occup Med 1992;34:311-16.

18 Costello J, Graham WGB. Vermont granite workers' mortality study. Am $J$ Ind Med 1988;13:483-97.

19 Hansen ES. A cohort mortality study of foundry workers. Am J Ind Med 1997; 32:223-33.

20 Muller J, Wheeler WC, Gentleman JF, et al. Study of mortality of Ontario miners: 1955-1977. Part I. NTIS Document No. DE88703584. Toronto, Ontario, Canada: Ontario Ministry of Labour, Ontario Workers' Compensation Board, Atomic Energy Control Board of Canada, 1983.

21 Steenland K, Brown D. Mortality study of gold miners exposed to silica and nonasbestiform amphibole minerals: an update with 14 more years of follow-up. Am J Ind Med 1995;27:217-29.

22 Reid PJ, Sluis-Cremer GK. Mortality of white South African gold miners. Occup Environ Med 1996:53:11-16.

23 Steenland K, Sanderson W. Lung cancer among industrial sand workers exposed to crystalline silica. Am J Epidemiol 2001;153:695-703.

24 IARC. IARC monographs on the evaluation of carcinogenic risks to humans: Silica, some silicates, coal dust and para-aramid fibrils. Vol 68 Lyon, France: World Health Organization, International Agency for Research on Cancer, 1997.

25 Steenland K, Stayner L. Silica, asbestos, man-made mineral fibers, and cancer. Cancer Causes Control 1997;8:491-503.

26 Nelson DE, Emont SL, Brackbill RM, et al. Cigarette smoking prevalence by occupation in the United States. J Occup Med 1994;36:516-25.

27 Hessel PA, Sluis-Cremer GK, Hnizdo E. Silica exposure, silicosis, and lung cancer: a necropsy study. Br J Ind Med 1990;47:4-9. 
28 McLaughlin JK, Chen J-Q, Dosemeci $M$, et al. A nested case-control study of lung cancer among silica exposed workers in China. $\mathrm{Br} J$ Ind Med 1992;49:167-71.

29 Checkoway H, Franzblau A. Is silicosis required for silica-associated lung cancer? Am J Ind Med 2000;37:252-9.

30 American Thoracic Society. Adverse effects of crystalline silica exposure. Am J Respir Crit Care Med 1997;155:761-8.

31 Balmes J. Silica exposure and tuberculosis: an old problem with some new twists [editorial]. J Occup Med 1990;32:1 14-15.

32 Sherson D, Lander F. Morbidity of pulmonary tuberculosis among silicotic and nonsilicotic foundry workers in Denmark. J Occup Med 1990;32:110-13.

33 Cowie RL. The epidemiology of tuberculosis in gold miners with silicosis Am J Respir Crit Care Med 1994;150:1460-2.

34 Radford EP, St Clair Renard KG. Lung cancer in Swedish iron miners exposed to low doses of radon daughters. N Engl J Med 1984;310:1485-94

35 Lawler AB, Mandel JS, Schuman LM, et al. A retrospective cohort mortality study of iron ore (hematite) miners in Minnesota. J Occup Med 1985;27:507-17.

36 Shannon H, Heller JG, Pron G, et al. Report of the Special Panel on the Ontario gold mining industry. Appendix A of Industrial Disease Standards Panel report to the Workers' Compensation Board of the Ontario gold mining industry. Toronto, Ontario, Canada: Ministry of Labour, 1987.

37 Miller AB, Scarpelli D, Weiss NS. Report of the scientific panel on "mortality from cancer among Ontario gold miners, 1955-1977." Appendix C of the Industrial Disease Standards Panel report to the Workers' Compensation Board of the Ontario gold mining industry. Toronto, Ontario, Canada: Ministry of Labour, 1987.

38 Kusiak R, Ritchie AC, Springer J, et al. Mortality from stomach cancer in Ontario miners. Br J Ind Med 1993;50:1 17-26.

39 Belli S, Comba P, Germani D, et al. Mortality study among lead-zinc Italian (Val Seriana) miners. Med Lav 1989;80:467-78.

40 Katsnelson BA, Mokronosova KA. Non-fibrous mineral dusts and malignant tumors. J Occup Med 1979;21:15-20.

41 Neuberger $M$, Kundi $M$. Occupational dust exposure and cancer mortality-results of a prospective cohort study. In: Simonato L, Fletcher AC, Saracci R, et al, eds. Occupational exposure to silica and cancer risk. Lyon, France: International Agency for Research on Cancer, 1990:65-73.

42 Hayes RB, Dosemeci $M$, Riscigno $M$, et al. Cancer mortality among jewelry workers. Am J Ind Med 1993;24:743-51.

43 Dubrow R, Gute DM. Cause-specific mortality among Rhode Island jewelry workers. Am J Ind Med 1987; 12:579-93.

44 Sparks PJ, Wegman DH. Cause of death among jewelry workers. J Occup Med 1980;22:733-6.

45 Blair A, Zahm SH. Cancer among farmers. Occup Med $1991 ; 6: 335-54$.

46 Zahm SH, Blair A. Cancer among migrant and seasonal farmworkers: an epidemiologic review and research agenda. Am J Ind Med 1993;24:753-66.

47 Parent M-É, Siemiatycki J, Fritschi L. Occupational exposures and gastric cancer. Epidemiology 1998;9:48-55.

48 Pan G, Takahashi K, Feng Y, et al. Nested case-control study of esophageal cancer in relation to occupational exposure to silica and other dusts. Am J Ind Med 1999;35:272-80.

49 Decoufle $\mathbf{P}$, Wood DJ. Mortality patterns among workers in a gray iron foundry. Am J Epidemiol 1979;109:667-75.

50 Amandus HE, Shy C, Wing S, et al. Silicosis and lung cancer in North Carolina dusty trades workers. Am J Ind Med 1991;20:57-70.

51 Goldsmith DF, Beaumont JJ, Morrin LA, et al. Respiratory cancer and other chronic disease mortality among silicotics in California. Am J Ind Med 1995;28:459-67

52 Costello J, Castellan RM, Swecker GS, et al. Mortality of a cohort of U.S. workers employed in the crushed stone industry, 1940-1980. Am J Ind Med 1995;27:625-40.

53 Checkoway H, Heyer NJ, Demers PA, et al. Mortality among workers in the diatomaceous earth industry. $\mathrm{Br} J$ Ind Med 1993;50:586-97.

54 Partanen T, Pukkala $E$, Vainio $H$, et al. Increased incidence of lung and skin cancer in Finnish silicotic patients. J Occup Med 1994;36:616-22.

55 Cherry N, Burgess G, McNamee R, et al. Initial findings from a cohort mortality study of British pottery workers. Appl Occup Environ Hyg 1995; 10:1042-5.

56 Guénel P, Højberg G, Lynge E. Cancer incidence among Danish stone workers. Scand J Work Environ Health 1989;15:265-70.

57 Smith DA, Germolec DR. Introduction to immunology and autoimmunity. Environ Health Perspect 1999;107(suppl 5):661-5.

58 D'Cruz D. Autoimmune diseases associated with drugs, chemicals and environmental factors. Toxicol Lett 2000;1 12-13:421-32.

59 Rao T, Richardson B. Environmentally induced autoimmune diseases: potential mechanisms. Environ Health Perspect 1999;107/suppl 5):737-42
60 Parks CG, Conrad K, Cooper GS. Occupational exposure to crystalline silica and autoimmune disease. Environ Health Perspect 1999;107/suppl 5):793-802.

61 Sluis-Cremer GK, Hessel PA, Hnizdo E, et al. Relationship between silicosis and rheumatoid arthritis. Thorax 1986;41:596-601.

62 Brown LM, Gridley G, Olsen JH, et al. Cancer risk and mortality patterns among silicotic men in Sweden and Denmark. J Occup Environ Med 1997;39:633-8.

63 Rosenman KD, Zhu Z. Pneumoconiosis and associated medical conditions. Am J Ind Med 1995;27:107-13.

64 Rosenman KD, Moore-Fuller M, Reilly M. Connective tissue disease and silicosis. Am J Ind Med 1999;35:375-81.

65 Klockars M, Koskela RS, Järvinen E, et al. Silica exposure and rheumatoid arthritis: a follow up study of granite workers, 1940-1981. Br Med J 1987;294:997-1000.

66 Turner S, Cherry N. Rheumatoid arthritis in workers exposed to silica in the pottery industry. Occup Environ Med 2000;57:443-7.

67 Olsson AR, Skogh T, Wingren GA. Occupational determinants for rheumatoid arthritis. Scand J Work Environ Health 2000;26:243-9.

68 Burns CJ, Laing TJ, Gillespie BW, et al. The epidemiology of scleroderma among women: assessment of risk from exposure to silicone and silica. J Rheumatol 1996;23:1904-11.

69 Bovenzi M, Barbone F, Betta A, et al. Scleroderma and occupational exposure. Scand J Work Environ Health 1995:21:289-92.

70 Silman AJ, Jones S. What is the contribution of occupational environmental factors to the occurrence of scleroderma in men? Ann Rheum Dis 1992; 51:1322-4.

71 Englert H, Small-McMahon J, Davis K, et al. Male systemic sclerosis and occupational silica exposure-a population-based study. Aust N Z J Med 2000;30:215-20

72 Lacey JV, Laing TJ, Gillespie BW, et al. Epidemiology of scleroderma among women: assessment of risk from exposure to silicone and silica. J Rheumatol 1997;24:1854-5.

73 Parks CG, Cooper GS, Nylander-French LA, et al. A population-based study of occupational exposure to crystalline silica and systemic lupus erythematosus [abstract]. Am J Epidemiol 2000;151:S82

74 Hogan SL, Satterly KK, Dooley MA, et al. Silica exposure in anti-neutrophil cytoplasmic autoantibody-associated glomerulonephritis and lupus nephritis. J Am Soc Nephrol 2001;12:134-42.

75 Sanchez-Roman J, Wichmann I, Salaberri J, et al. Multiple clinical and biological autoimmune manifestations in 50 workers after occupational exposure to silica. Ann Rheum Dis 1993;52:534-8.

76 Conrad K, Mehlhorn J, Lüthke K, et al. Systemic lupus erythematosus after heavy exposure to quartz dust in uranium mines: clinical and serological characteristics. Lupus 1996;5:62-9.

77 Costabel U, Hunninghake GW, Sarcoidosis Statement Committee. ATS/ERS/WASOG statement on sarcoidosis. Eur Respir J 1999;14:735-7.

78 Nuyts GD, Van Vlem E, De Vos A, et al. Wegener granulomatosis is associated to exposure to silicon compounds: a case-control study. Nephrol Dial Transplant 1995;10:1162-5.

79 Satterly KK, Hogan SL, Nachman PH, et al. ANCA-associated diseases with renal involvement (ANCA-GN) but not lupus nephritis (LN) are associated with silica exposure [abstract]. Clin Exp Immunol 1998;112(suppl 1):25.

80 Gregorini G, Ferioli A, Donato F, et al. Association between silica exposure and necrotizing crescentic glomerulonephritis with p-ANCA and anti-MPO antibodies: a hospital-based case-control study. Adv Exp Med Biol 1993;336:435-40.

81 Calvert GM, Steenland K, Palu S. End-stage renal disease among silica-exposed gold miners: a new methodology for assessing incidence among epidemiologic cohorts. JAMA 1997;277:1219-23.

82 Steenland K, Sanderson W, Calvert GM. Kidney disease and arthritis in a cohort study of workers exposed to silica. Epidemiology 2001:12:405-12.

83 Rapiti E, Sperati A, Miceli M, et al. End stage renal disease among ceramic workers exposed to silica. Occup Environ Med 1999:56:559-61.

84 Steenland NK, Thun N, Ferguson W, et al. Occupational and other exposures associated with male-end-stage renal disease: a case/control study. Am J Public Health 1990;80:153-7.

85 Rosenman KD, Moore-Fuller M, Reilly M. Kidney disease and silicosis. Nephron 2000;85:14-19.

86 Koskela RS, Klockars M, Järvinen E, et al. Mortality and disability among granite workers. Scand J Work Environ Health 1987;13:18-25.

87 Carta P, Cocco P, Picchiri G. Lung cancer mortality and airways obstruction among metal miners exposed to silica and low levels of radon daughters. Am J Ind Med 1994;25:489-506.

88 Cocco PL, Carta P, Flore V, et al. Lung cancer mortality among female mine workers exposed to silica. J Occup Med 1994;36:894-8. 